\title{
Development of a manualized protocol of massage therapy for clinical trials in osteoarthritis
}

\author{
Ather $\mathrm{Ali}^{1{ }^{*}}$, Janet Kahn${ }^{2}$, Lisa Rosenberger ${ }^{3}$ and Adam I Perlman ${ }^{4}$
}

\begin{abstract}
Background: Clinical trial design of manual therapies may be especially challenging as techniques are often individualized and practitioner-dependent. This paper describes our methods in creating a standardized Swedish massage protocol tailored to subjects with osteoarthritis of the knee while respectful of the individualized nature of massage therapy, as well as implementation of this protocol in two randomized clinical trials.

Methods: The manualization process involved a collaborative process between methodologic and clinical experts, with the explicit goals of creating a reproducible semi-structured protocol for massage therapy, while allowing some latitude for therapists' clinical judgment and maintaining consistency with a prior pilot study.

Results: The manualized protocol addressed identical specified body regions with distinct 30- and 60-min protocols, using standard Swedish strokes. Each protocol specifies the time allocated to each body region. The manualized 30- and 60-min protocols were implemented in a dual-site 24-week randomized dose-finding trial in patients with osteoarthritis of the knee, and is currently being implemented in a three-site 52-week efficacy trial of manualized Swedish massage therapy. In the dose-finding study, therapists adhered to the protocols and significant treatment effects were demonstrated.

Conclusions: The massage protocol was manualized, using standard techniques, and made flexible for individual practitioner and subject needs. The protocol has been applied in two randomized clinical trials. This manualized Swedish massage protocol has real-world utility and can be readily utilized both in the research and clinical settings.
\end{abstract}

Trial registration: Clinicaltrials.gov NCT00970008 (18 August 2009)

Keywords: Massage, Manualization, Clinical trial, Manual therapy, Swedish

\section{Background}

Among the challenges in research in complementary and alternative medicine (CAM) is the necessity to design clinical trials that are methodologically rigorous as well as consistent with prevailing clinical practice patterns [1-3]. This difficulty has been mentioned in trials of botanical medicines [3], mind-body interventions [4], and manual therapies [5,6]. Many CAM disciplines espouse patient-centered care that often results in some individualization of treatment. Thus, standardization of interventions for clinical trials poses a particular challenge. Clinical trial design of manual therapies may be

\footnotetext{
* Correspondence: ather.ali@yale.edu

'Department of Pediatrics, Yale University School of Medicine, 2 Church Street South, New Haven, CT 06519, USA

Full list of author information is available at the end of the article
}

especially challenging since techniques are often practitioner-dependent as well as patient-oriented $[7,8]$.

Massage therapy is one of the most popular CAM techniques in the USA [9]. Between 2002 and 2007, the 1 -year prevalence of use of massage by the US adult population increased from 5\% (10 million) to $8.3 \%$ (18 million) [9]. Massage is generally used, with some research support, to relieve pain from musculoskeletal disorders and cancer, rehabilitate sports injuries, reduce stress, increase relaxation, decrease feelings of anxiety and depression, and aid in general wellness [10-24].

The identification of massage therapy for patients with osteoarthritis as a research priority derives directly from a CDC-funded systematic evidence mapping project applied to CAM [25], leading to our pilot study evaluating the safety and efficacy of a 1-h whole body Swedish 
massage in adults with osteoarthritis of the knee [26]. After 8 weeks of massage therapy (biweekly $\times 4$ weeks, weekly $\times 4$ weeks), scores on the Western Ontario and McMaster Universities Arthritis Index (WOMAC) [27] global score improved significantly (55\%) from baseline $(P<0.001)$, as did the scores in each subdomain (pain, stiffness, and physical functional disability), with effects persisting 8 weeks after treatment cessation [26]. Swedish massage techniques were chosen for their practical utility; being the most widely taught and practiced massage method that is well defined procedurally, and safe when administered by trained massage therapists [28-30].

Manualization was initially developed for the creation of standardized treatment protocols for psychotherapy, both to help provide methodologic rigor for evaluation, and as a means to provide specificity and guidelines regarding individualized treatment [31]. Massage therapy, as an intervention in clinical trials has similar needs for methodologic rigor to standardize patient-customized treatments and practitioner variation [32,33]. In 2002, Schnyer and Allen published their methodology on developing treatment manuals for acupuncture interventions used in NIH-funded trials. These manuals served as a means to facilitate the training process, enable evaluation of conformity and competence, and increase the ability to identify the active therapeutic ingredients in clinical trials of acupuncture [34]. The Institute of Medicine has noted that manualization is an integral component for rigorous research on CAM therapies [35].

This investigative team collaborated again in a 2 -year single-blinded randomized controlled dose-finding study, aiming to identify an optimal-practical dose and treatment regimen of an 8-week course of Swedish massage for osteoarthritis of the knee. The intervention development phase of this dose-finding study incorporated a formal manualization process. Here we describe our approach in developing a standardized massage intervention tailored to subjects with osteoarthritis of the knee while respectful of the individualized nature of massage therapy [34], as well as the implementation of this manualized protocol into two NIH-supported randomized controlled trials.

\section{Methods}

Development of the manualization process, conducted over the course of 2 months, involved the input of methodologic and clinical experts. The manualization process was aided by a committee organized and under the direction of the former Research Director (JK) of the Massage Therapy Research Consortium (MTRC). The MTRC was a consortium of schools in the United States and Canada collaborating to build research capacity and to advance research in the field of massage.

Four meetings were held by telephone conference call. Participants included members of the investigative team, massage therapists from both clinical sites, and massage therapy researchers. Each meeting reiterated the overarching goals of the manualization process:

1. To create a reproducible, semi-structured protocol for massage therapy for osteoarthritis of the knee, while allowing for some latitude based on therapists' clinical judgment. Four distinct 'doses' varying on duration (30 min vs. $60 \mathrm{~min}$ ) and frequency (weekly or biweekly) to assess dose-response effects.

2. To be consistent with the protocol delivered during the pilot study [26]. Thus, only the Swedish massage techniques of effleurage, petrissage, tapotement, vibration (including rocking or jostling), friction, and skin-rolling were to be used. These are standard Swedish strokes and massage techniques taught in schools accredited by the Commission on Massage Therapy Accreditation (COMTA) [36].

The manualization team tailored the treatment protocols to the over-arching goals of subsequent clinical trials; that is to determine the efficacy of a standardized Swedish massage protocol for treatment of patients with osteoarthritis of the knee. The putative mechanisms of massage as related to treating osteoarthritis (relaxation, reducing inflammation, improving flexibility) were considered when designing the protocol.

The protocol of the dose-finding study, consent form and all recruitment materials were approved by the Institutional Review Boards of the University of Medicine and Dentistry of New Jersey (Newark, NJ, USA), Griffin Hospital (Derby, CT, USA), and the Saint Barnabas Medical Center (Livingston, NJ, USA). The study was conducted in accordance with the Declaration of Helsinki [37].

\section{Results}

The manualized protocol specifies the body regions to be addressed, with distinct 30 - and $60-\mathrm{min}$ protocols, as well as the standard Swedish strokes to be used (effleurage, petrissage, tapotement, vibration, friction, and skin rolling) [38] (see Table 1). Each protocol specifies the time allocated to various body regions (lower/upper limbs, lower/upper back, head, neck, chest) and specific areas of emphasis. The order of body regions, patient position (supine or prone), technique sequence, or technique type is left to the discretion of the therapist to account for individual practitioner preference and patient needs. 
Table 130 - and 60-minute massage protocols

\begin{tabular}{|c|c|c|}
\hline \multicolumn{3}{|r|}{ Allowed Swedish massage techniques: } \\
\hline \multicolumn{3}{|c|}{ Effleurage, petrissage, tapotement, vibration, friction, and skin rolling } \\
\hline \multicolumn{3}{|r|}{ 30-minute protocol ( 25 minutes of table time) } \\
\hline Region & Time allotted & Distribution \\
\hline Lower limbs & $\begin{array}{l}12 \text { to } 15 \text { min } \\
\text { (45\% to } 50 \% \text { of session) }\end{array}$ & $\begin{array}{c}\text { From knee down including lower leg, ankle, and foot. From knee up including hips, pelvis, } \\
\text { buttocks, and thigh. }\end{array}$ \\
\hline Upper body & $\begin{array}{l}8 \text { to } 12 \text { min } \\
\text { (36\% to } 44 \% \text { of session) }\end{array}$ & Lower and upper back; head/neck/chest. \\
\hline Discretionary & $\begin{array}{l}2 \text { to } 5 \text { min } \\
\text { (6\% to } 19 \% \text { of session) }\end{array}$ & Therapist to expand treatment to other affected areas; that is rib cage, flank, upper limbs, et cetera. \\
\hline \multicolumn{3}{|r|}{ 60-minute protocol (55 minutes of table time ${ }^{a}$ ) } \\
\hline Lower limbs & $\begin{array}{l}20 \text { to } 27.5 \text { min } \\
\text { (45\% to } 50 \% \text { of session) }\end{array}$ & $\begin{array}{l}\text { From knee down including lower leg, ankle, and foot. From knee up including hips, pelvis, } \\
\text { buttocks, and thigh. }\end{array}$ \\
\hline Upper body & $\begin{array}{l}15 \text { to } 24 \text { min } \\
\text { (36\% to } 44 \% \text { of session) }\end{array}$ & Lower and upper back; head, neck, and chest. \\
\hline Discretionary & $\begin{array}{l}3.5 \text { to } 20 \text { min } \\
\text { (6\% to } 19 \% \text { of session) }\end{array}$ & $\begin{array}{l}\text { Therapist to expand treatment to other affected areas; that is rib cage, flank, } \\
\text { upper limbs, et cetera. }\end{array}$ \\
\hline
\end{tabular}

The protocol further specifies intentions/attentions for the study therapists consistent with massage therapy practice, specifically:

1. Assess and address relevant imbalances in posture

2. In general, seek to establish symmetry

3. Strengthen muscles around knee joint

4. Compensate weak muscles

5. Disperse stress to bring balance

6. Decrease sympathetic activity

7. Diffuse inflammation

8. Reduce inhibition in anti-gravity muscles

Each study therapist was trained in the protocol, and signed a form attesting to adherence to the manualized massage protocol after each massage session. No deviations from the protocol were reported for the duration of the dose-finding trial at either site.

The manualization team agreed that the knee must be regarded as a functional unit. Thus, the protocol explicitly does not specify the percent of time to be spent directly on structures of the knee. Rather, time variables included the upper and lower leg, both including the knee (see Table 1).

The manualized 30- and 60-min protocols were implemented in a 24-week randomized dose-finding trial of massage therapy for osteoarthritis of the knee [39]. Subjects $(n=125)$ were randomized to one of four regimens of the manualized massage intervention (30 min or $60 \mathrm{~min}$ weekly or biweekly) or to a usual care control. Outcomes were assessed at baseline, 8, 16, and 24 weeks and included the WOMAC, visual analog pain scale, range of motion, and time to walk 50 feet. The initial randomization occurred in October 2009 and the last subject completed the 8-week intervention in October 2010.

Both 60-min regimens (weekly or biweekly) demonstrated significantly improved WOMAC global scores (24.0 points, $95 \%$ CI varied from 15.3 to 32.7 ) compared to usual care (6.3 points, $95 \%$ CI 0.1 to 12.8 ) at the primary endpoint of 8 weeks. Further, the 60 -min regimens demonstrated significant improvements in WOMAC subscales of pain and functionality, as well as the visual analog pain scale compared to usual care. No significant differences were seen in range of motion at 8 weeks, and no significant effects were seen in any outcome measure at 24 weeks compared to usual care. A dose-response curve based on WOMAC global scores shows increasing effect with greater total time of massage; with 60-min doses scoring significantly better than 30-min doses. No significant differences were seen in WOMAC global scores between the 60-min doses (weekly or biweekly) [39].

This trial thus established an 'optimal-practical' dose (60-min once-weekly) of this manualized Swedish massage regimen for osteoarthritis of the knee. This decision was based on the superiority of the $60-\mathrm{min}$ compared to $30-\mathrm{min}$ regimens, the essentially similar outcomes of the two 60-min doses, the convenience of a once-weekly protocol (compared to biweekly), cost savings, and consistency with a typical real-world massage protocol [39].

This optimized dose of manualized Swedish massage therapy is currently being implemented in a large-scale $(n=222) \mathrm{NIH}$-funded 52-week efficacy trial of massage therapy for osteoarthritis of the knee at three clinical sites [40]. 


\section{Discussion}

Clinical trials of massage therapy are inherently challenged by an inability to blind practitioner and recipient. Furthermore, massage practices are heterogeneous with procedures utilized from different schools of massage incorporating a variety of techniques. Some of these schools include Swedish massage, neuromuscular, myofascial, Chinese, other Asian, medical, osteopathic, or naturopathic manipulative therapies [41].

Massage is a pleasant and desirable intervention and is safe when delivered by trained practitioners using standard Swedish techniques [28]. Demonstrating the efficacy of massage therapy in clinical trials requires reproducible treatment regimens.

To our knowledge, this is the first report to describe the manualization of massage therapy. The feasibility of this protocol is demonstrated by implementing this standardized regimen in two clinical sites in the randomized dose-finding trial [39], as well as in a larger three-site efficacy trial [40].

A few published reports of implementing standardized Swedish massage regimens in randomized trials exist. Patterson et al. published a standardized massage (and control) regimen in a clinical trial assessing fatigue reduction in cancer chemotherapy, though no results have been published [36]. Sharpe et al. published the results of a pilot randomized trial assessing the effects of a standardized Swedish massage regimen $v s$. guided relaxation on stress and wellbeing in a pilot study $(n=54)$ [42], though there are no reports of implementing this regimen in a larger sample. Taylor et al. also report using a standardized Swedish massage protocol though the protocol was not described to the point that the intervention could be reproduced [43]. Cherkin et al. assessed a standardized Swedish protocol ('relaxation massage') [44], other massage techniques ('structural massage'), and continuing usual care in a three-arm randomized controlled trial for patients with chronic back pain. Both massage regimens were found to be superior to usual care, with no clinically meaningful differences seen between the relaxation and structural massage arms [7].

Other randomized trials of Swedish massage therapy have not used standardized massage interventions, compromising external validity and reducing the ability to replicate positive results $[45,46]$.

The concept of 'dose' has never been formally defined for massage. Prior to determining specific study protocols, the manualization team had to operationally define 'dose' of massage therapy. If dose, for example, was defined only by the length of time, it may be assumed that a single 60-min session and two 30-min sessions would be equivalent. This assumption was tested by assessing the effects of frequency of massage therapy. Thus, in our manualization process, two variables germane to dosing were assessed: frequency of massage therapy and duration of treatment. Frequency was varied between weekly or biweekly sessions, based on practicality and current practice standards. Duration of treatment was negotiated by the expert panel to provide a dose that is clinically effective while avoiding possible overtreatment.

Finally the team explored the issue of what constituted 'massage for the knee'. In this study the team chose to view the knee in its functionality and distribute the apportioned time not to specific muscles, tendons or ligaments, but rather to the two regions of the knee and lower leg (ankle, foot, and lower leg) and the knee and upper leg (including hips, pelvis, buttocks, and thighs).

Massage treatments are often focused on a particular functional issue or anatomic region, though they typically also include some broader treatment to promote relaxation [7]. Relaxation has been thought to be helpful to many healing processes, and from a massage therapy perspective, to aid in whole body integration to supporting proper gait and biomechanics of the joint(s). Thus, the protocol involved regions beyond the knee; time was allotted to the upper and lower back, neck, chest, and head.

One of the limitations of this manualized Swedish massage protocol is that the protocol may not be as efficacious as real-world practice as fully individualized treatment is precluded. In addition, other techniques (that is, neuromuscular and myofascial) may be more effective in altering posture and gait in ways that might affect osteoarthritis symptoms and progression. The one known study comparing Swedish massage with myofascial and neuromuscular techniques for treatment of back pain showed no significant difference in ability to affect pain or function [7].

\section{Conclusions}

The resulting massage protocol was manualized [40], using standard Swedish techniques [26,28], and made flexible for individual subject variability. This manualized Swedish massage protocol has successfully been implemented in a dual-site dose-finding clinical trial and a three-site efficacy trial. The manualized Swedish massage protocol has real-world utility and can be readily utilized in clinical trials and clinical practice.

\begin{abstract}
Abbreviations
CAM: Complementary and Alternative Medicine; CDC: Centers for Disease Control and Prevention; MTRC: Massage Therapy Research Consortium; NCCAM: National Center for Complementary and Alternative Medicine; $\mathrm{NIH}$ : National Institutes of Health; WOMAC: Western Ontario and McMaster Universities Arthritis Index.
\end{abstract}

Competing interests

The authors declare that they have no competing interests.

Authors' contributions

AA led the manualization process, participated in the design and

coordination of the study, and drafted the manuscript. JK provided technical 
expertise in massage therapy. LR assisted in the clinical trial and provided critical review of the manuscript. AP conceived of the study, and participated in its design and coordination, and critically reviewed the manuscript. All authors read and approved the final manuscript.

\section{Acknowledgements}

We thank the study subjects for their participation. Licensed massage therapists Linda Winz, Michael Yablonsky, Susan Kmon, and Lee Stang provided massages for study subjects. Mary Carola, Margaret Rogers, Carl Milak, Anna Davidi, and Dr. Valentine Njike provided technical and administrative support

This publication was made possible by grants R01AT004623 and K23AT006703 from the National Center for Complementary and Alternative Medicine (NCCAM) at the National Institutes of Health. Its contents are solely the responsibility of the authors and do not necessarily represent the official views of NCCAM. The sponsors had no role in study design, data collection and analysis, decision to publish, or preparation of the manuscript.

\section{Author details}

${ }^{1}$ Department of Pediatrics, Yale University School of Medicine, 2 Church Street South, New Haven, CT 06519, USA. ${ }^{2}$ College of Medicine, University of Vermont, 240 Maple Street, Burlington, VT 05401, USA. ${ }^{3}$ Yale-Griffin Prevention Research Center, Griffin Hospital, 130 Division Street, Derby, C T

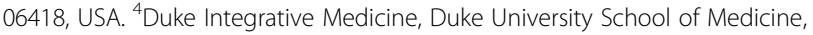
3475 Erwin Road, Durham, NC 27710, USA.

Received: 26 April 2012 Accepted: 27 September 2012 Published: 4 October 2012

\section{References}

1. Nahin RL: Identifying and pursuing research priorities at the National Center for Complementary and Alternative Medicine. FASEB J 2005, 19:1209-1215

2. Nahin RL, Straus SE: Research into complementary and alternative medicine: problems and potential. BMJ 2001, 322:161-164.

3. Kinsel JF, Straus SE: Complementary and alternative therapeutics: rigorous research is needed to support claims. Annu Rev Pharmacol Toxicol 2003, 43:463-484.

4. Ospina MB, Bond K, Karkhaneh M, Buscemi N, Dryden DM, Barnes V, Carlson $L E$, Dusek JA, Shannahoff-Khalsa D: Clinical trials of meditation practices in health care: characteristics and quality. J Altern Complement Med 2008, 14:1199-1213.

5. Hawk C, Long CR, Rowell RM, Gudavalli MR, Jedlicka J: A randomized trial investigating a chiropractic manual placebo: a novel design using standardized forces in the delivery of active and control treatments. J Altern Complement Med 2005, 11:109-117.

6. Vernon H, MacAdam K, Marshall V, Pion M, Sadowska M: Validation of a sham manipulative procedure for the cervical spine for use in clinical trials. J Manipulative Physiol Ther 2005, 28:662-666.

7. Cherkin DC, Sherman KJ, Kahn J, Wellman R, Cook AJ, Johnson E, Erro J, Delaney K, Deyo RA: A comparison of the effects of 2 types of massage and usual care on chronic low back pain: a randomized, controlled trial. Ann Intern Med 2011, 155:1-9.

8. Frampton S, Charmel P (Eds): Putting Patients First: Designing and Practicing Patient-Centered Care. San Francisco, CA: Jossey-Bass Publishers, Inc; 2008.

9. Barnes PM, Bloom B, Nahin RL: Complementary and alternative medicine use among adults and children: United States, 2007. Natl Health Stat Rep 2008, 12:1-23.

10. Wentworth LJ, Briese LJ, Timimi FK, Sanvick CL, Bartel DC, Cutshall SM, Tilbury RT, Lennon R, Bauer BA: Massage therapy reduces tension, anxiety, and pain in patients awaiting invasive cardiovascular procedures. Prog Cardiovasc Nurs 2009, 24:155-161.

11. Listing M, Reisshauer A, Krohn M, Voigt B, Tjahono G, Becker J, Klapp BF, Rauchfuss M: Massage therapy reduces physical discomfort and improves mood disturbances in women with breast cancer. Psychooncology 2009, 18:1290-1299

12. Kutner JS, Smith MC, Corbin L, Hemphill L, Benton K, Mellis BK, Beaty B, Felton S, Yamashita TE, Bryant LL, Fairclough DL: Massage therapy versus simple touch to improve pain and mood in patients with advanced cancer: a randomized trial. Ann Intern Med 2008, 149:369-379.
13. Jane S-W, Wilkie DJ, Gallucci BB, Beaton RD, Huang H-Y: Effects of a full-body massage on pain intensity, anxiety, and physiological relaxation in Taiwanese patients with metastatic bone pain: a pilot study. J Pain Symptom Manage 2009, 37:754-763.

14. Hernandez-Reif M, Field T, Krasnegor J, Theakston H: Lower back pain is reduced and range of motion increased after massage therapy. Int J Neurosci 2001, 106:131-145.

15. Frey Law LA, Evans S, Knudtson J, Nus S, Scholl K, Sluka KA: Massage reduces pain perception and hyperalgesia in experimental muscle pain: a randomized, controlled trial. J Pain 2008, 9:714-721.

16. Field T, Figueiredo B, Hernandez-Reif M, Diego M, Deeds O, Ascencio A: Massage therapy reduces pain in pregnant women, alleviates prenatal depression in both parents and improves their relationships. J Bodyw Mov Ther 2008, 12:146-150.

17. Ezzo J, Haraldsson BG, Gross AR, Myers CD, Morien A, Goldsmith CH, Bronfort G, Peloso PM: Massage for mechanical neck disorders: a systematic review. Spine 2007, 32:353-362.

18. Downey L, Diehr P, Standish LJ, Patrick DL, Kozak L, Fisher D, Congdon S, Lafferty WE: Might massage or guided meditation provide "means to a better end"? Primary outcomes from an efficacy trial with patients at the end of life. J Palliat Care 2009, 25:100-108.

19. Corbin LW, Mellis BK, Beaty BL, Kutner JS: The use of complementary and alternative medicine therapies by patients with advanced cancer and pain in a hospice setting: a multicentered, descriptive study. J Palliat Med 2009, 12:7-8.

20. Billhult A, Lindholm C, Gunnarsson R, Stener-Victorin E: The effect of massage on immune function and stress in women with breast cancer-a randomized controlled trial. Auton Neurosci 2009, 150:111-115.

21. Poole AR, lonescu M, Fitzcharles MA, Billinghurst RC: The assesment of cartilage degradation in vivo: development of and immunoassay for the measurement in body fluids of type II collagen cleaved by collagenases. $\mathrm{J}$ Immunol Methods 2004, 294:145-153.

22. Ernst E: Complementary and alternative medicine for pain management in rheumatic disease. Curr Opin Rheumatol 2002, 14:58-62.

23. Back C, Tam H, Lee E, Haraldsson B: The effects of employer-provided massage therapy on job satisfaction, workplace stress, and pain and discomfort. Holist Nurs Pract 2009, 23:19-31.

24. Bauer BA, Cutshall SM, Wentworth $\sqcup$, Engen D, Messner PK, Wood CM, Brekke KM, Kelly RF, Sundt TM 3rd: Effect of massage therapy on pain, anxiety, and tension after cardiac surgery: a randomized study. Complement Ther Clin Pract 2010, 16:70-75.

25. Katz DL, Williams A-I, Girard C, Goodman J, Comerford B, Behrman A, Bracken MB: The evidence base for complementary and alternative medicine: methods of Evidence Mapping with application to CAM. Altern Ther Health Med 2003, 9:22-30.

26. Perlman Al, Sabina A, Williams AL, Njike WY, Katz DL: Massage therapy for osteoarthritis of the knee: a randomized controlled trial. Arch Intern Med 2006, 166:2533-2538

27. Bellamy N, Buchanan WW, Goldsmith CH, Campbell J, Stitt LW: Validation study of WOMAC: a health status instrument for measuring clinically important patient relevant outcomes to antirheumatic drug therapy in patients with osteoarthritis of the hip or knee. J Rheumatol 1988, 15:1833-1840.

28. Ernst E: The safety of massage therapy. Rheumatology 2003, 42:1101-1106.

29. Cambron JA, Dexheimer J, Coe P, Swenson R: Side-effects of massage therapy: a cross-sectional study of 100 clients. J Altern Complement Med 2007, 13:793-796.

30. National Center for Complementary and Alternative Medicine: NCCAM Backgrounder: Massage Therapy: An Introduction. Publication No. D327. Bethesda, MD: NCCAM; 2010.

31. Scaturo DJ: The evolution of psychotherapy and the concept of manualization: an integrative perspective. Pro Psychol Res Prac 2001, 32:522-530

32. Levin JS, Glass TA, Kushi LH, Schuck JR, Steele L, Jonas WB: Quantitative methods in research on complementary and alternative medicine. $A$ methodological manifesto. NIH Office of Alternative Medicine. Med Care 1997, 35:1079-1094.

33. Carter B: Methodological issues and complementary therapies: researching intangibles? Complement Ther Nurs Midwifery 2003, 9:133-139.

34. Schnyer RN, Allen Jj: Bridging the gap in complementary and alternative medicine research: manualization as a means of promoting 
standardization and flexibility of treatment in clinical trials of acupuncture. J Altern Complement Med 2002, 8:623-634.

35. Institute of Medicine of the National Academies: Need for innovative designs in research on CAM and conventional medicine. In Complementary and Alternative Medicine in the United States. Washington, DC: The National Academies Press; 2005:108-128.

36. Patterson M, Maurer S, Adler SR, Avins AL: A novel clinical-trial design for the study of massage therapy. Complement Ther Med 2008, 16:169-176.

37. World Medical Association: World Medical Association Declaration of Helsinki: ethical principles for medical research involving human subjects. JAMA 2000, 284:3043-3045.

38. Geiringer SR, de Lateur BJ: Physiatric therapeutics. 3. Traction, manipulation, and massage. Arch Phys Med Rehabil 1990, 71:S264-S266.

39. Perlman Al, Ali A, Njike WY, Hom D, Davidi A, Gould-Fogerite S, Milak C, Katz DL: Massage therapy for osteoarthritis of the knee: a randomized dosefinding trial. PLoS One 2012, 7:e30248.

40. National Center for Complementary and Alternative Medicine; Duke University: Exploring Massage Benefits for Arthritis of the Knee (EMBARK). In ClinicalTrials.gov [Internet]. Bethesda, MD: National Library of Medicine; 2012. NLM Identifier: NCT01537484. [http://clinicaltrials.gov/show/ NCT01537484].

41. Cambron JA, Dexheimer J, Coe P: Changes in blood pressure after various forms of therapeutic massage: a preliminary study. $J$ Altern Complement Med 2006, 12:65-70.

42. Sharpe PA, Williams HG, Granner ML, Hussey JR: A randomised study of the effects of massage therapy compared to guided relaxation on well-being and stress perception among older adults. Complement Ther Med 2007, 15:157-163.

43. Taylor AG, Galper DI, Taylor P, Rice LW, Andersen W, Irvin W, Wang XQ, Harrell FE Jr: Effects of adjunctive Swedish massage and vibration therapy on short-term postoperative outcomes: a randomized, controlled trial. J Altern Complement Med 2003, 9:77-89.

44. Cherkin DC, Sherman KJ, Kahn J, Erro JH, Deyo RA, Haneuse SJ, Cook AJ: Effectiveness of focused structural massage and relaxation massage for chronic low back pain: protocol for a randomized controlled trial. Trials 2009, 10:96.

45. Cronfalk BS, Ternestedt BM, Strang P: Soft tissue massage: early intervention for relatives whose family members died in palliative cancer care. J Clin Nurs 2010, 19:1040-1048.

46. Aourell M, Skoog M, Carleson J: Effects of Swedish massage on blood pressure. Complement Ther Clin Pract 2005, 11:242-246.

doi:10.1186/1745-6215-13-185

Cite this article as: Ali et al.: Development of a manualized protocol of massage therapy for clinical trials in osteoarthritis. Trials 2012 13:185.

\section{Submit your next manuscript to BioMed Central and take full advantage of:}

- Convenient online submission

- Thorough peer review

- No space constraints or color figure charges

- Immediate publication on acceptance

- Inclusion in PubMed, CAS, Scopus and Google Scholar

- Research which is freely available for redistribution 